\title{
Massively Multiplexed Affinity Characterization of Therapeutic Antibodies Against SARS-CoV-2 Variants
}

\author{
Authors: Emily Engelhart $\dagger^{1}$, Randolph Lopez $\dagger^{* 1}$, Ryan Emerson ${ }^{1}$, Charles Lin $^{1}$, Colleen \\ Shikany ${ }^{1}$, Daniel Guion ${ }^{1}$, Mary Kelley ${ }^{1}$, David Younger ${ }^{1}$
}

Affiliations:

\author{
${ }^{1}$ A-Alpha Bio. Seattle, WA. USA \\ *Corresponding author. Email: rlopez@aalphabio.com. \\ $\dagger$ These authors contributed equally to this work
}

\begin{abstract}
Antibody therapies represent a valuable tool to reduce COVID-19 deaths and hospitalizations. Multiple antibody candidates have been granted emergency use authorization by the FDA and many more are in clinical trials. Most antibody therapies for COVID-19 are engineered to bind to the receptor-binding domain (RBD) of the SARS-CoV-2 Spike protein and disrupt its interaction with ACE2. Notably, several SARS-CoV-2 strains have accrued mutations throughout the RBD that improve ACE2 binding affinity, 15 enhance viral transmission, and escape some existing antibody therapies. Here, we measure the binding affinity of 33 therapeutic antibodies against a large panel of SARS-CoV-2 variants and related strains of clinical significance to determine epitopic residues, determine which mutations result in loss of binding, and predict how future RBD variants may impact antibody efficacy.
\end{abstract}

One-Sentence Summary: By measuring protein binding in vitro, we identify which clinical antibodies retain binding to various mutant SARS-CoV-2 strains. 


\section{Introduction}

Antibody therapies represent a valuable tool to reduce COVID-19 deaths and alleviate the burden on healthcare systems. During the vaccine rollout, antibody therapies to treat COVID-19 serve as a stopgap to save lives. Once vaccines are widely available, antibody therapies will continue to play an essential role in treating patients who are unvaccinated, such as the immunocompromised, and those infected with viral variants that escape vaccine protection. Antibody therapies can be developed quickly, making them well suited for rapid response to newly emerging strain variants, and have proven to reduce both viral loads and hospitalizations $(1,2)$. Multiple antibody candidates have been granted emergency use authorization by the FDA and many more are in phase 2 and phase 3 clinical trials (3-5).

Most antibody therapies for COVID-19 are engineered to bind to the receptor-binding domain (RBD) of the SARS-CoV-2 Spike protein and disrupt its interaction with angiotensin-converting enzyme 2 (ACE2) (6-10). Since the first human transmission of COVID-19 over one year ago, SARS-CoV-2 has undergone significant antigenic drift arising from mutations throughout the RBD that improve ACE2 binding affinity, enhance viral transmission, and generate resistance to existing antibody therapies (11-16). Understanding the impact of observed and likely RBD variants on the effectiveness of antibody therapies is of critical importance.

A handful of antibody therapies have been granted emergency use authorization by the FDA, over a dozen are in late-stage clinical development, and many more are in preclinical development (17). However, previous efforts to measure the effect of RBD variants on the efficacy of antibody candidates for COVID-19 have mostly been limited to characterizing individual CoV-2 RBD variants on a small number of antibody candidates $(8,18-23)$. A notable exception is the method introduced by Starr et al. which involves the construction of a yeast surface display library of RBD variants and enables the complete mapping of binding between a single antibody and all single mutations of the $\operatorname{RBD}(14,15,24,25)$. The low antibody throughput of this method, however, precludes characterization of a wide variety of clinically relevant antibodies.

The AlphaSeq assay, previously described as yeast synthetic agglutination, is presented here as a method for overcoming existing throughput challenges for characterizing the binding profiles of tens of antibodies against thousands of RBD variants (26). Here, we leveraged the AlphaSeq assay to measure approximately 178,760 protein-protein interactions (PPIs) between 33 therapeutically 35 relevant antibody candidates and most single-amino-acid mutations to SARS-CoV-2 RBD, along with selected widely circulating RBD variants containing multiple mutations. The PPI measurements are analyzed to derive key epitope residues for each antibody, determine individual or multiple mutations that result in loss of binding for each antibody, and predict how future RBD variants may impact antibody efficacy. Figure 1 presents the AlphaSeq assay and its application to antibody/RBD binding in schematic form.

\section{Results}

First, to determine the epitope for each antibody an AlphaSeq experiment was performed where 33 antibodies were screened against a site-saturation mutagenesis (SSM) library comprising of (after library preparation and sequencing) approximately 75\% of all single-residue mutants of 165 sites within the SARS-CoV-2 RBD (Fig. 2A, S1, S2). While many RBD sites were intolerant to 
mutations (i.e., observed binding was poor across all antibodies and all mutants at that site), other sites revealed differential patterns of mutation-sensitivity among antibodies indicating epitopic diversity among the tested antibodies (Fig. 2B). These sites allowed us to identify the epitope targeted by each antibody. Specifically, a pairwise binding comparison across all antibodies was carried out for each residue of the SARS-CoV-2 RBD (Fig. 2C). For each site in the RBD included in the SSM library, all mutant affinities (scaled to each antibody's affinity to WT RBD) were compared between the two antibodies with a Mann-Whitney U test (Table S7). For each antibody, sites at which differential sensitivity (Bonferroni-corrected p-values $\leq .05$ ) was observed for at least 4 other antibodies were considered putative epitope residues (Table S8). Overall, 21 antibodies had residues that were found to have putative epitope residues (Fig. 2D). For antibodies with known RBD-Ab structures, we found that our results correctly place key epitopic residues at the interface between the antibody and RBD (Fig. 2E). Our results agree with previously published epitope data for COR-101, Imdevimab, Casirivimab, Bamlavimab, CC12.1 (19, 27, 28) while providing new insight into the epitopes targeted by the remaining antibodies and therefore allow us to prospectively identify which RBD sites should be of particular concern for antibody binding in new strains.

Next, a second AlphaSeq experiment was performed to assess binding of 33 clinically relevant antibodies and ACE2 against a curated panel of coronavirus RBD variants. Included were 34 unique SARS-CoV-2 RBD variants with single, double, or triple mutations, including 5 CDCdefined variants of concern, B.1.1.7, B.1.351, P.1, B.1.427, and B.1.429, and four related coronavirus RBDs (Fig. 3A). From this single experiment, we determined the tolerance or enhancement of ACE2 binding, quantitatively measured the binding of each antibody to each SARS-CoV-2 variant and characterized the cross-reactivity profile of each antibody to related coronavirus strains (Fig. S3, Table S9).

Measuring the interactions with ACE2 revealed many SARS-CoV-2 RBD variants with tighter receptor binding. In particular, all 5 of the CDC's variants of concern showed increased binding affinity to ACE2, which is supported by previously reported affinities for B.1.1.7 and B.1.351 (29) and molecular dynamics simulations for B.1.1.7, B.1.351, and P.1 (30).

The dataset includes 9 antibodies in clinical trials with publicly available sequences (Table S2) (31). We observed a wide range of binding to the panel of SARS-CoV-2 RBD variants (Fig. 3B). Notably, we found good concordance with previous literature reports for most antibody-variant 35 interactions (Table S1). Of these 9 antibodies, 3 antibodies have been extensively studied in the literature: Imdevimab, Casirivimab and Bamlanivimab $(14,18,22,23,25,32,33)$. We recapitulated the binding profiles for the B.1.1.7, B.1.351, and P.1 variants to Imdevimab, Casirivimab and Bamlanivimab $(23,32,33)$. To summarize: we observe no significant changes in binding to the B.1.1.7 variant for Imdevimab, Casirivimab or Bamlanivimab. We observed a decrease in binding affinity for Casirivimab and Bamlanivimab to B.1.351 and P.1 variants whereas Imdevimab retained WT binding. Our findings with these 4 antibodies are highly consistent with previous literature reports. To date, there have been minimal or no reports on Sotrovimab, Regdanvimab, Tixagevimab, Cilgavimab, and COR-101 antibodies $(19,24)$. We find that Regdanvimab and COR-101 display reduced binding affinity to B.1.1.7, B.1.351, and P.1 variants. Tixagevimab has reduced binding affinity to B.1.351, and P.1 variants but maintains WT binding affinity with the B.1.1.7 variant. Whereas Sotrovimab and COR-101 show no changes in binding affinity to the B.1.1.7, B.1.351, and P.1 variants. 
As part of the same experiment, cross-reactivity was evaluated by measuring antibody binding to four additional RBDs from related coronaviruses: SARS-CoV-1, LYRa11, WIV1, and RaTG13. Some antibodies were found to be highly specific to SARS-CoV-2, including Imdevimab, Bamlanivimab, Regdanvimab, Tixagevimab, Cilgavimab, and COR-101. In contrast, Casirivimab, Sotrovimab, and Etesevimab demonstrate varying degrees of cross-reactivity.

From two AlphaSeq assays, we mapped binding of ACE2 and $33 \mathrm{CoV}$ antibodies against a panel of SARS-CoV-2 RBD variants, including B.1.1.7, B.1.351, and P.1, and identified key epitope residues for each antibody. This experiment has provided for the first time a comprehensive view of the impact of potential escape mutants (including several strains of substantial clinical concern) on the binding of RBD-targeted antibody therapeutics. For the small fraction of the dataset for which binding has been assayed previously, or for which the epitope is known via crystal structure, good agreement with previous methods establishes the reliability of AlphaSeq as a method. A full understanding of the impact of RBD mutations on the binding of therapeutic antibodies is essential to prioritize the development of therapies effective against the widest possible variety of circulating and newly emerging viral variants, and to enable the eventual possibility of regional or even personal prioritization of the most effective therapies for circulating SARS-CoV-2 variants.

\section{References and Notes}

1. R. L. Gottlieb, A. Nirula, P. Chen, J. Boscia, B. Heller, J. Morris, G. Huhn, J. Cardona, B. Mocherla, V. Stosor, I. Shawa, P. Kumar, A. C. Adams, J. Van Naarden, K. L. Custer, M. Durante, G. Oakley, A. E. Schade, T. R. Holzer, P. J. Ebert, R. E. Higgs, N. L. Kallewaard, J. Sabo, D. R. Patel, P. Klekotka, L. Shen, D. M. Skovronsky, Effect of Bamlanivimab as Monotherapy or in Combination With Etesevimab on Viral Load in Patients With Mild to Moderate COVID-19: A Randomized Clinical Trial. JAMA 325, 632-644 (2021) https://doi.org/10.1001/jama.2021.0202.

2. D. M. Weinreich, S. Sivapalasingam, T. Norton, S. Ali, H. Gao, R. Bhore, B. J. Musser, Y. Soo, D. Rofail, J. Im, C. Perry, C. Pan, R. Hosain, A. Mahmood, J. D. Davis, K. C. Turner, A. T. Hooper, J. D. Hamilton, A. Baum, C. A. Kyratsous, Y. Kim, A. Cook, W. Kampman, A. Kohli, Y. Sachdeva, X. Graber, B. Kowal, T. DiCioccio, N. Stahl, L. Lipsich, N. Braunstein, G. Herman, G. D. Yancopoulos, I. Trial, REGN-COV2, a Neutralizing Antibody Cocktail, in Outpatients with Covid-19. N Engl J Med 384, 238251 (2021) https://doi.org/10.1056/NEJMoa2035002.

3. USFDA, Coronavirus (COVID-19) Update: FDA Authorizes Monoclonal Antibody for Treatment of COVID-19. 11/09/2020 https://www.fda.gov/news-events/pressannouncements/coronavirus-covid-19-update-fda-authorizes-monoclonal-antibodytreatment-covid-19.

4. USFDA, Coronavirus (COVID-19) Update: FDA Authorizes Monoclonal Antibodies for Treatment of COVID-19. 11/21/2020 https://www.fda.gov/news-events/pressannouncements/coronavirus-covid-19-update-fda-authorizes-monoclonal-antibodiestreatment-covid-19.

5. Y. Sun, M. Ho, Emerging antibody-based therapeutics against SARS-CoV-2 during the global pandemic. Antibody Therapeutics 3, 246-256 (2020) https://doi.org/10.1093/abt/tbaa025. 
6. S. F. Ahmed, A. A. Quadeer, M. R. McKay, Preliminary Identification of Potential Vaccine Targets for the COVID-19 Coronavirus (SARS-CoV-2) Based on SARS-CoV Immunological Studies. Viruses 12, (2020) https://doi.org/10.3390/v12030254.

7. E. Fast, R. B. Altman, B. Chen, Potential T-cell and B-cell Epitopes of 2019-nCoV. bioRxiv, (2020) https://doi.org/10.1101/2020.02.19.955484.

8. M. Hoffmann, H. Kleine-Weber, S. Schroeder, N. Kruger, T. Herrler, S. Erichsen, T. S. Schiergens, G. Herrler, N. H. Wu, A. Nitsche, M. A. Muller, C. Drosten, S. Pohlmann, SARS-CoV-2 Cell Entry Depends on ACE2 and TMPRSS2 and Is Blocked by a Clinically Proven Protease Inhibitor. Cell 181, 271-280 e278 (2020) https://doi.org/10.1016/j.cell.2020.02.052.

9. D. Wrapp, N. Wang, K. S. Corbett, J. A. Goldsmith, C. L. Hsieh, O. Abiona, B. S. Graham, J. S. McLellan, Cryo-EM structure of the 2019-nCoV spike in the prefusion conformation. Science 367, 1260-1263 (2020) https://doi.org/10.1126/science.abb2507.

10. A. C. Walls, Y. J. Park, M. A. Tortorici, A. Wall, A. T. McGuire, D. Veesler, Structure, Function, and Antigenicity of the SARS-CoV-2 Spike Glycoprotein. Cell 181, 281-292 e286 (2020) https://doi.org/10.1016/j.cell.2020.02.058.

11. A. J. Greaney, T. N. Starr, P. Gilchuk, S. J. Zost, E. Binshtein, A. N. Loes, S. K. Hilton, J. Huddleston, R. Eguia, K. H. D. Crawford, A. S. Dingens, R. S. Nargi, R. E. Sutton, N. Suryadevara, P. W. Rothlauf, Z. Liu, S. P. J. Whelan, R. H. Carnahan, J. E. Crowe, Jr., J. D. Bloom, Complete Mapping of Mutations to the SARS-CoV-2 Spike Receptor-Binding Domain that Escape Antibody Recognition. Cell Host Microbe 29, 44-57 e49 (2021) https://doi.org/10.1016/j.chom.2020.11.007.

12. Q. Li, J. Wu, J. Nie, L. Zhang, H. Hao, S. Liu, C. Zhao, Q. Zhang, H. Liu, L. Nie, H. Qin, M. Wang, Q. Lu, X. Li, Q. Sun, J. Liu, L. Zhang, X. Li, W. Huang, Y. Wang, The Impact of Mutations in SARS-CoV-2 Spike on Viral Infectivity and Antigenicity. Cell 182, 1284-1294 e1289 (2020) https://doi.org/10.1016/j.cell.2020.07.012.

13. J. Ou, Z. Zhou, R. Dai, S. Zhao, X. Wu, J. Zhang, W. Lan, L. Cui, J. Wu, D. Seto, J. Chodosh, G. Zhang, Q. Zhang, V367F mutation in SARS-CoV-2 spike RBD emerging during the early transmission phase enhances viral infectivity through increased human ACE2 receptor binding affinity. bioRxiv, (2021)

https://doi.org/10.1101/2020.03.15.991844.

14. T. N. Starr, A. J. Greaney, A. Addetia, W. W. Hannon, M. C. Choudhary, A. S. Dingens, J. Z. Li, J. D. Bloom, Prospective mapping of viral mutations that escape antibodies used to treat COVID-19. Science 371, 850-854 (2021) https://doi.org/10.1126/science.abf9302.

15. T. N. Starr, A. J. Greaney, S. K. Hilton, D. Ellis, K. H. D. Crawford, A. S. Dingens, M. J. Navarro, J. E. Bowen, M. A. Tortorici, A. C. Walls, N. P. King, D. Veesler, J. D. Bloom, Deep Mutational Scanning of SARS-CoV-2 Receptor Binding Domain Reveals Constraints on Folding and ACE2 Binding. Cell 182, 1295-1310 e1220 (2020) https://doi.org/10.1016/j.cell.2020.08.012.

16. L. Zhang, C. B. Jackson, H. Mou, A. Ojha, H. Peng, B. D. Quinlan, E. S. Rangarajan, A. Pan, A. Vanderheiden, M. S. Suthar, W. Li, T. Izard, C. Rader, M. Farzan, H. Choe, SARS-CoV-2 spike-protein D614G mutation increases virion spike density and infectivity. Nat Commun 11, 6013 (2020) https://doi.org/10.1038/s41467-020-19808-4.

17. P. C. Taylor, A. C. Adams, M. M. Hufford, I. de la Torre, K. Winthrop, R. L. Gottlieb, Neutralizing monoclonal antibodies for treatment of COVID-19. Nat Rev Immunol, (2021) https://doi.org/10.1038/s41577-021-00542-x. 
18. A. Baum, B. O. Fulton, E. Wloga, R. Copin, K. E. Pascal, V. Russo, S. Giordano, K. Lanza, N. Negron, M. Ni, Y. Wei, G. S. Atwal, A. J. Murphy, N. Stahl, G. D.

Yancopoulos, C. A. Kyratsous, Antibody cocktail to SARS-CoV-2 spike protein prevents rapid mutational escape seen with individual antibodies. Science 369, 1014-1018 (2020) https://doi.org/10.1126/science.abd0831.

19. F. Bertoglio, V. Fühner, M. Ruschig, P. A. Heine, U. Rand, T. Klünemann, D. Meier, N. Langreder, S. Steinke, R. Ballmann, K.-T. Schneider, K. D. R. Roth, P. Kuhn, P. Riese, D. Schäckermann, J. Korn, A. Koch, S. Zock-Emmenthal, M. Becker, M. Scholz, G. M. S. G. Moreira, E. V. Wenzel, G. Russo, H. S. P. Garritsen, S. Casu, A. Gerstner, G. Roth, A. Hermann, T. Schirrmann, S. Dübel, A. Frenzel, J. Van den Heuvel, L. Čičin-Šain, M. Schubert, M. Hust, A SARS-CoV-2 neutralizing antibody selected from COVID-19 patients by phage display is binding to the ACE2-RBD interface and is tolerant to known RBD mutations. bioRxiv, (2020) https://doi.org/10.1101/2020.12.03.409318.

20. J. Dong, S. J. Zost, A. J. Greaney, T. N. Starr, A. S. Dingens, E. C. Chen, R. E. Chen, J. B. Case, R. E. Sutton, P. Gilchuk, J. Rodriguez, E. Armstrong, C. Gainza, R. S. Nargi, E. Binshtein, X. Xie, X. Zhan, P. Y. Shi, J. Logue, S. Weston, M. E. McGrath, M. B. Frieman, T. Brady, K. Tuffy, H. Bright, Y. M. Loo, P. McTamney, M. Esser, R. H. Carnahan, M. S. Diamond, J. D. Bloom, J. E. Crowe, Genetic and structural basis for recognition of SARS-CoV-2 spike protein by a two-antibody cocktail. bioRxiv, (2021) https://doi.org/10.1101/2021.01.27.428529.

21. B. Schepens, L. van Schie, W. Nerinckx, K. Roose, W. Van Breedam, D. Fijalkowska, S. Devos, W. Weyts, S. De Cae, S. Vanmarcke, C. Lonigro, H. Eeckhaut, D. Van Herpe, J. Borloo, A. F. Oliveira, J. P. Catani, S. Creytens, D. De Vlieger, G. Michielsen, J. C. Zavala Marchan, G. D. Moschonas, I. Rossey, K. Sedeyn, A. Van Hecke, X. Zhang, L. Langendries, S. Jacobs, S. ter Horst, L. Seldeslachts, L. Liesenborghs, R. Boudewijns, H. J. Thibaut, K. Dallmeier, G. V. Velde, B. Weynand, J. Beer, D. Schnepf, A. Ohnemus, I. Remory, C. S. Foo, R. Abdelnabi, P. Maes, S. J. F. Kaptein, J. Rocha-Pereira, D. Jochmans, L. Delang, F. Peelman, P. Staeheli, M. Schwemmle, N. Devoogdt, D. Tersago, M. Germani, J. Heads, A. Henry, A. Popplewell, M. Ellis, K. Brady, A. Turner, B. Dombrecht, C. Stortelers, J. Neyts, N. Callewaert, X. Saelens, Drug development of an affinity enhanced, broadly neutralizing heavy chain-only antibody that restricts SARSCoV-2 in rodents. bioRxiv, (2021) https://doi.org/10.1101/2021.03.08.433449.

22. E. C. Thomson, L. E. Rosen, J. G. Shepherd, R. Spreafico, A. da Silva Filipe, J. A. Wojcechowskyj, C. Davis, L. Piccoli, D. J. Pascall, J. Dillen, S. Lytras, N. Czudnochowski, R. Shah, M. Meury, N. Jesudason, A. De Marco, K. Li, J. Bassi, A. O'Toole, D. Pinto, R. M. Colquhoun, K. Culap, B. Jackson, F. Zatta, A. Rambaut, S. Jaconi, V. B. Sreenu, J. Nix, I. Zhang, R. F. Jarrett, W. G. Glass, M. Beltramello, K. Nomikou, M. Pizzuto, L. Tong, E. Cameroni, T. I. Croll, N. Johnson, J. Di Iulio, A. Wickenhagen, A. Ceschi, A. M. Harbison, D. Mair, P. Ferrari, K. Smollett, F. Sallusto, S. Carmichael, C. Garzoni, J. Nichols, M. Galli, J. Hughes, A. Riva, A. Ho, M. Schiuma, M. G. Semple, P. J. M. Openshaw, E. Fadda, J. K. Baillie, J. D. Chodera, I. C. Investigators, C.-G. U. Consortium, S. J. Rihn, S. J. Lycett, H. W. Virgin, A. Telenti, D. Corti, D. L. Robertson, G. Snell, Circulating SARS-CoV-2 spike N439K variants maintain fitness while evading antibody-mediated immunity. Cell 184, 1171-1187 e1120 (2021) https://doi.org/10.1016/j.cell.2021.01.037.

23. R. Wang, Q. Zhang, J. Ge, W. Ren, R. Zhang, J. Lan, B. Ju, B. Su, F. Yu, P. Chen, H. Liao, Y. Feng, X. Li, X. Shi, Z. Zhang, F. Zhang, Q. Ding, T. Zhang, X. Wang, L. Zhang, 
SARS-CoV-2 variants resist antibody neutralization and broaden host ACE2 usage. bioRxiv, (2021) https://doi.org/10.1101/2021.03.09.434497.

24. T. N. Starr, N. Czudnochowski, F. Zatta, Y. J. Park, Z. Liu, A. Addetia, D. Pinto, M. Beltramello, P. Hernandez, A. J. Greaney, R. Marzi, W. G. Glass, I. Zhang, A. S. Dingens, J. E. Bowen, J. A. Wojcechowskyj, A. De Marco, L. E. Rosen, J. Zhou, M. Montiel-Ruiz, H. Kaiser, H. Tucker, M. P. Housley, J. di Iulio, G. Lombardo, M. Agostini, N. Sprugasci, K. Culap, S. Jaconi, M. Meury, E. Dellota, E. Cameroni, T. I. Croll, J. C. Nix, C. Havenar-Daughton, A. Telenti, F. A. Lempp, M. S. Pizzuto, J. D. Chodera, C. M. Hebner, S. P. J. Whelan, H. W. Virgin, D. Veesler, D. Corti, J. D. Bloom, G. Snell, Antibodies to the SARS-CoV-2 receptor-binding domain that maximize breadth and resistance to viral escape. bioRxiv, (2021) https://doi.org/10.1101/2021.04.06.438709.

25. T. N. Starr, A. J. Greaney, A. S. Dingens, J. D. Bloom, Complete map of SARS-CoV-2 RBD mutations that escape the monoclonal antibody LY-CoV555 and its cocktail with LY-CoV016. bioRxiv, (2021) https://doi.org/10.1101/2021.02.17.431683.

26. D. Younger, S. Berger, D. Baker, E. Klavins, High-throughput characterization of protein-protein interactions by reprogramming yeast mating. Proc Natl Acad Sci US A 114, 12166-12171 (2017) https://doi.org/10.1073/pnas.1705867114.

27. J. Hansen, A. Baum, K. E. Pascal, V. Russo, S. Giordano, E. Wloga, B. O. Fulton, Y. Yan, K. Koon, K. Patel, K. M. Chung, A. Hermann, E. Ullman, J. Cruz, A. Rafique, T. Huang, J. Fairhurst, C. Libertiny, M. Malbec, W. Y. Lee, R. Welsh, G. Farr, S. Pennington, D. Deshpande, J. Cheng, A. Watty, P. Bouffard, R. Babb, N. Levenkova, C. Chen, B. Zhang, A. Romero Hernandez, K. Saotome, Y. Zhou, M. Franklin, S. Sivapalasingam, D. C. Lye, S. Weston, J. Logue, R. Haupt, M. Frieman, G. Chen, W. Olson, A. J. Murphy, N. Stahl, G. D. Yancopoulos, C. A. Kyratsous, Studies in humanized mice and convalescent humans yield a SARS-CoV-2 antibody cocktail. Science 369, 1010-1014 (2020) https://doi.org/10.1126/science.abd0827.

28. M. Yuan, H. Liu, N. C. Wu, C. D. Lee, X. Zhu, F. Zhao, D. Huang, W. Yu, Y. Hua, H. Tien, T. F. Rogers, E. Landais, D. Sok, J. G. Jardine, D. R. Burton, I. A. Wilson, Structural basis of a shared antibody response to SARS-CoV-2. Science 369, 1119-1123 (2020) https://doi.org/10.1126/science.abd2321.

29. M. Ramanathan, I. D. Ferguson, W. Miao, P. A. Khavari, SARS-CoV-2 B.1.1.7 and B.1.351 Spike variants bind human ACE2 with increased affinity. bioRxiv, (2021) https://doi.org/10.1101/2021.02.22.432359.

30. G. Nelson, O. Buzko, P. Spilman, K. Niazi, S. Rabizadeh, P. Soon-Shiong, Molecular dynamic simulation reveals E484K mutation enhances spike RBD-ACE2 affinity and the combination of E484K, K417N and N501Y mutations (501Y.V2 variant) induces conformational change greater than N501Y mutant alone, potentially resulting in an escape mutant. bioRxiv, (2021) https://doi.org/10.1101/2021.01.13.426558.

31. L. Yang, W. Liu, X. Yu, M. Wu, J. M. Reichert, M. Ho, COVID-19 antibody therapeutics tracker: a global online database of antibody therapeutics for the prevention and treatment of COVID-19. Antib Ther 3, 205-212 (2020) https://doi.org/10.1093/abt/tbaa020.

32. M. Hoffmann, P. Arora, R. Groß, A. Seidel, B. Hörnich, A. Hahn, N. Krüger, L. Graichen, H. Hofmann-Winkler, A. Kempf, M. S. Winkler, S. Schulz, H.-M. Jäck, B. Jahrsdörfer, H. Schrezenmeier, M. Müller, A. Kleger, J. Münch, S. Pöhlmann, SARSCoV-2 variants B.1.351 and B.1.1.248: Escape from therapeutic antibodies and antibodies induced by infection and vaccination. bioRxiv, (2021) https://doi.org/10.1101/2021.02.11.430787. 
33. H. Liu, P. Wei, Q. Zhang, Z. Chen, K. Aviszus, W. Downing, S. Peterson, L. Reynoso, G. P. Downey, S. K. Frankel, J. Kappler, P. Marrack, G. Zhang, 501Y.V2 and 501Y.V3 variants of SARS-CoV-2 lose binding to Bamlanivimab in vitro. bioRxiv, (2021) https://doi.org/10.1101/2021.02.16.431305.

Acknowledgments: We thank Dr. Jesse Bloom and Tyler Starr for their help with antibody and RBD variant selection.

Funding: National Science Foundation. Small Business Innovation Research Program Phase Award \# 2033772. (RL)

Author contributions: Conceptualization: DY, RL, EE, RE. Formal analysis: RL, EE, RE. Funding acquisition: DY, RL. Investigation: EE, CL, MK, DG, CS. Methodology: RL. Project administration: RL, EE, MK. Supervision: RL. Visualization: RL, EE, RE. Writing - original draft: DY, RL, EE, RE. Writing - review \& editing: DY, RL, EE, RE, CL

Competing interests: R.L. and D.Y. are the founders and current employees of A-Alpha Bio, Inc. (A-Alpha Bio) and own stock / stock options of A-Alpha Bio. E.E., R.E., C.L, M.K, C.S. and D.G. are employees of A-Alpha Bio; all employees own stock / stock options of A-Alpha Bio. A-Alpha Bio has a pending patent application (US16/856,506) relating to certain research described in this article.

Data and materials availability: Code is available at https:/github.com/A-

AlphaBio/cov2_antibodies_variants. Protein sequences are included in supplementary tables $2 \&$ 3. Raw affinity data is available in supplementary tables 4 and 5.

\section{Supplementary Materials}

Materials and Methods 


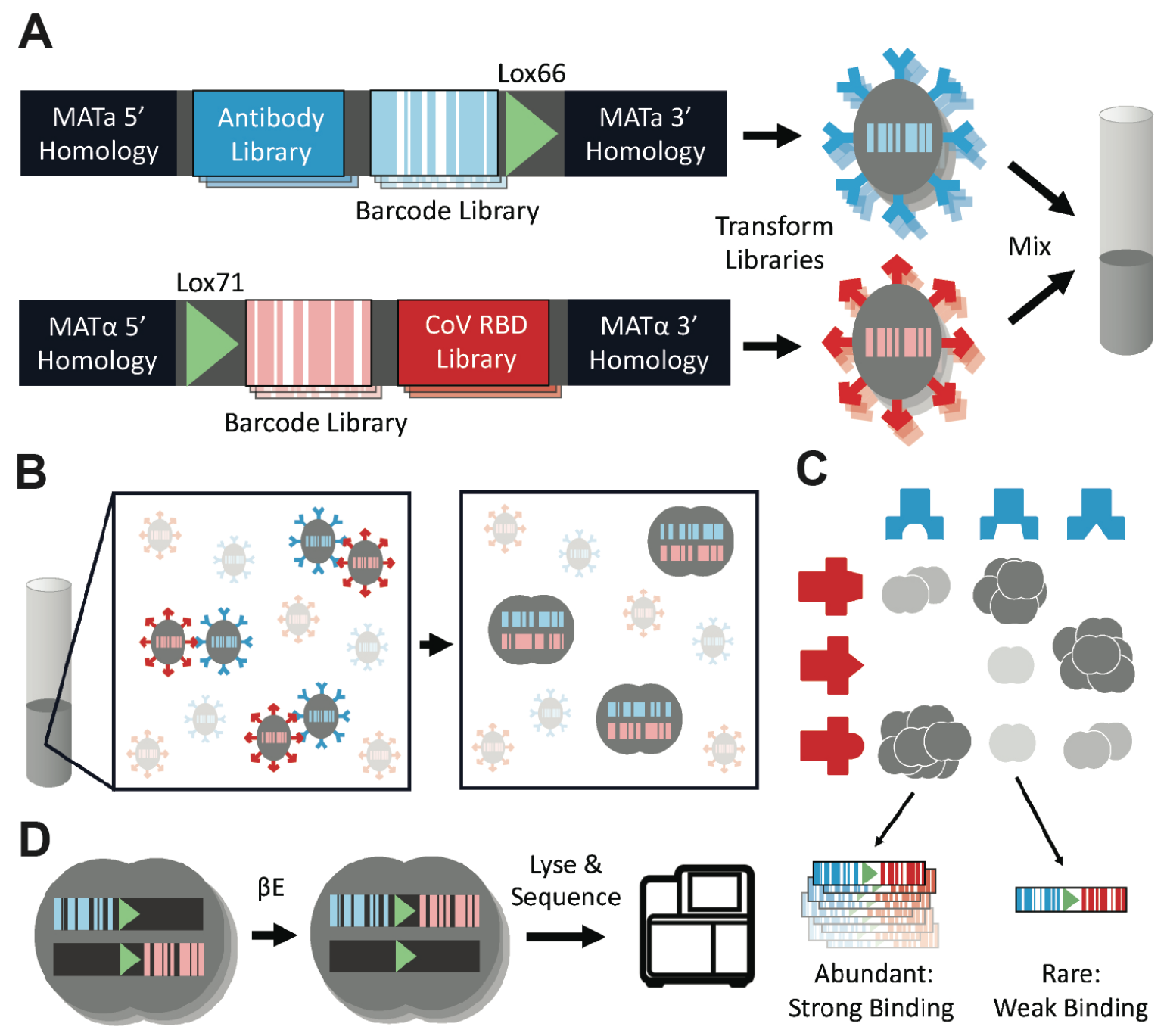

Figure 1: Using AlphaSeq to characterize interactions between an antibody library and a library of coronavirus RBD variants in high throughput. A) Two DNA fragment libraries are constructed with homology to the MATa or MAT $\alpha$ genome for integration into the chromosome. Each library contains a diversity of proteins of interest, either antibodies or RBD variants, for display on the yeast cell surface, a diversity of randomized 25 nucleotide DNA barcodes, and a lox recombination site. MATa and MAT $\alpha$ yeast strains lacking expression of native sexual agglutination proteins are transformed with their respective fragment library and subsequently mixed in liquid culture. B) In liquid culture, MATa-MAT $\alpha$ agglutination is facilitated by interactions between surface displayed antibodies and RBD variants. Agglutination leads to mating between MATa and MAT $\alpha$ haploid cells to produce a diploid cell. C) The number of diploids formed by a haploid pair is dependent on the interaction strength between the antibody and RBD variant expressed on their surfaces. D) Diploid cells are cultured with $\beta$-Estradiol to induce for CRE recombinase expression and recombine the engineered chromosome to pair DNA barcodes. Diploids are then lysed and sequenced to count the abundance of each barcode pair and determine the relative interaction strength between each antibody and coronavirus RBD variant. 
A

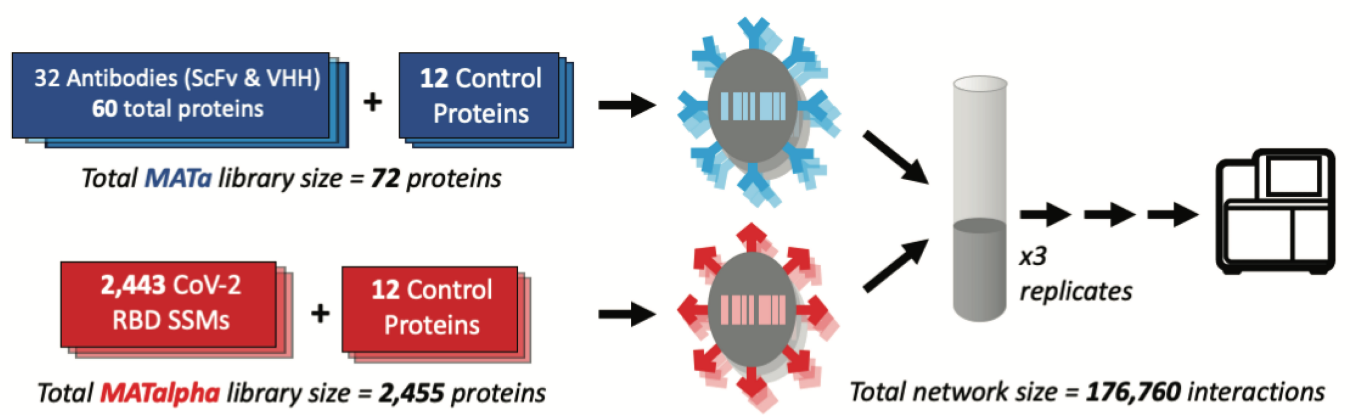

B

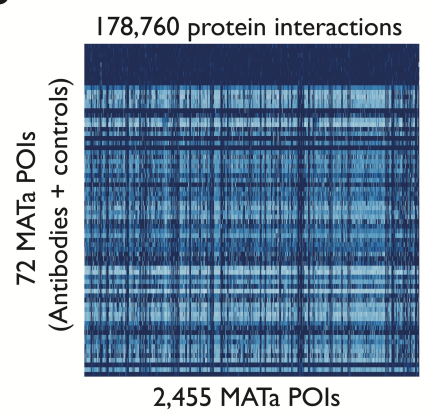

D

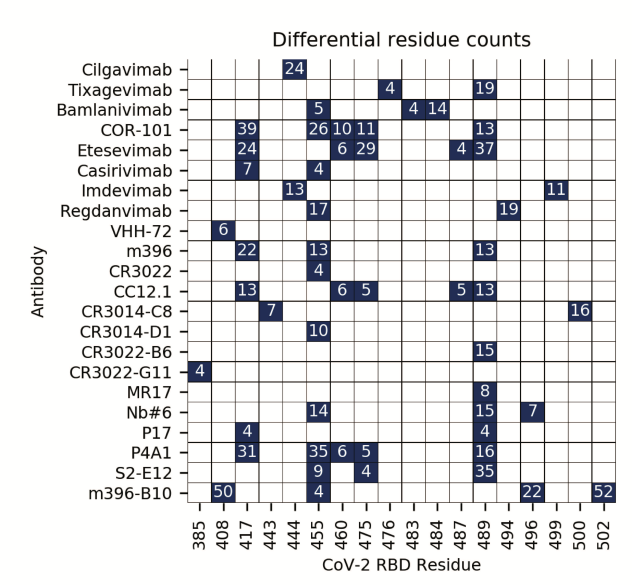

C Pairwise comparison of binding

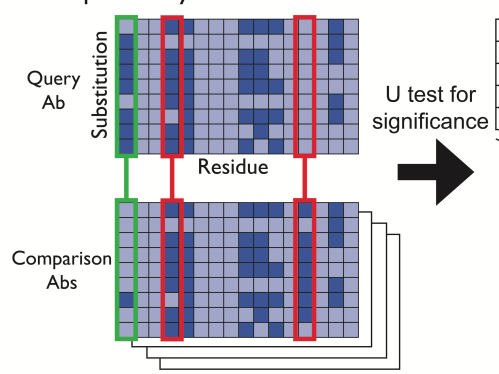

Filtering by significance and number of repeated observations

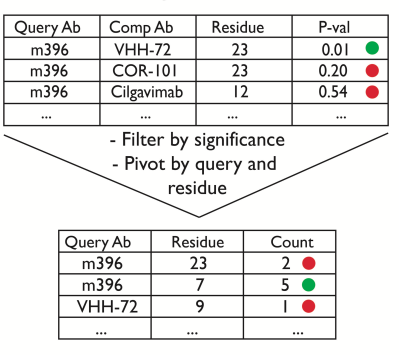

E
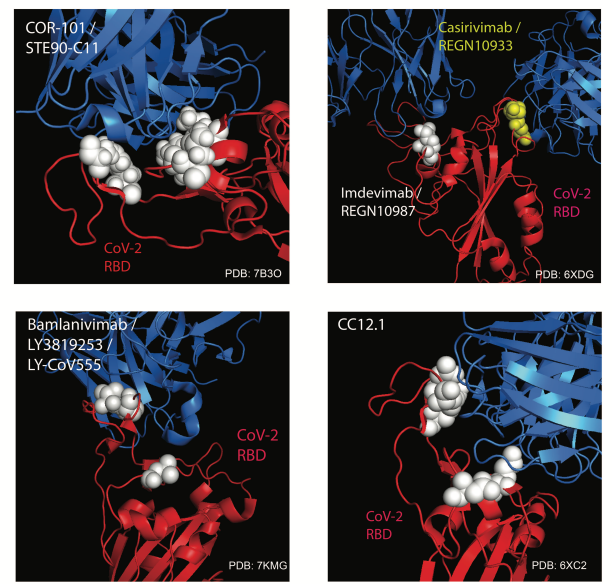

Figure 2. A) Schematic of epitope mapping AlphaSeq experiment, comparing antibodies against a CoV-2 RBD SSM library. B) Heatmap of AlphaSeq binding data showing all interactions measured in the assay in $\log 10 \mathrm{KD}(\mathrm{nM})$. RBD-CoV-2 intolerant substitutions results in loss binding for all antibodies in the set and appear as vertical dark blue streaks. C) Method summary for determination of epitope residues; each antibody was compared against all others, and at each RBD site a Mann-Whitney U test was performed to determine if binding was more impacted by a RBD mutations at that site in one antibody; results were filtered by U-test significance and for significance in 4 or more pairwise comparisons. D) Summary of epitope determination results -for each RBD site \& antibody (summing results from LH and HL orientations where both were tested), \# of pairwise comparisons with significant results. E) Representative antibodies (in blue) with known structure binding to RBD (in red), with residues called as epitope locations marked in white or yellow. 
A

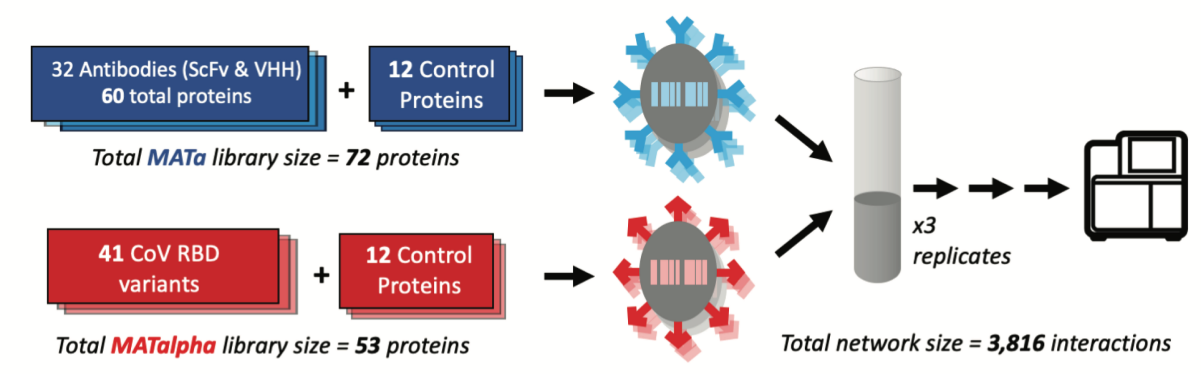

B

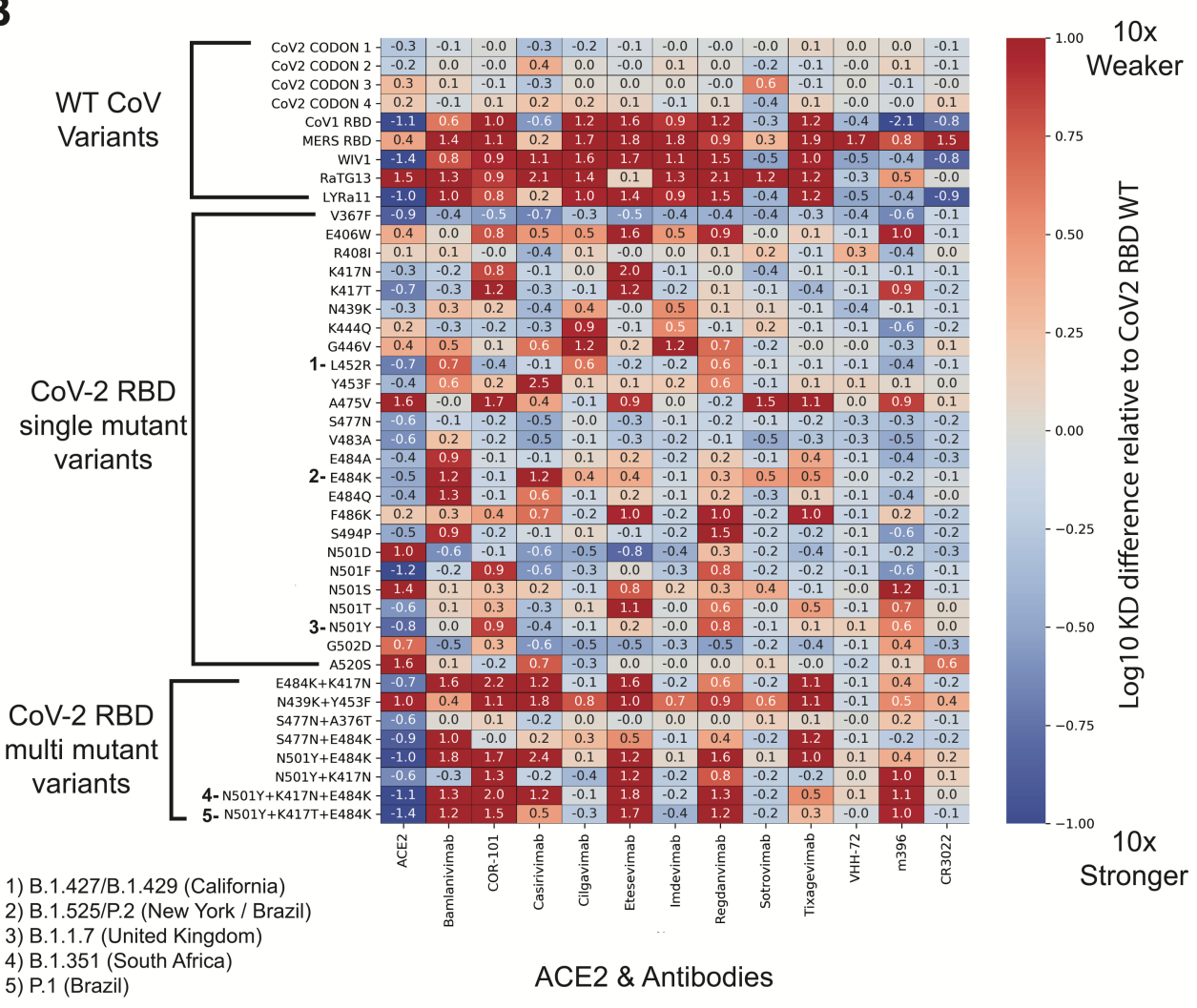

Figure 3. A) Schematic of AlphaSeq experiment, comparing antibodies against a curated panel of coronavirus RBD variants. B) Binding affinity of selected SARS-CoV-2 RBD variants to selected antibodies. Antibodies (or human ACE2) are on the x-axis, SARS-CoV-2 RBD variants are on the y-axis; in each column, values are mean difference in predicted binding affinity (measured on a $\log 10$ scale) between a given $\mathrm{CoV}$ variant and WT SARS-CoV-2 RBD for each antibody. Values below 0 (blue) represent improved binding relative to WT SARS-CoV-2 RBD and values above 0 (red) represent reduced binding affinity. In these data, Cilgavimab/AZD1061, Imdevimab/REGN10987 and Sotrovimab/GSK4182136 retain high affinity for the widest variety of clinically relevant RBD variants. 